\section{FUNCTIONAL NERVOUS DISORDERS OF THE HEART.*}

BY

R. TRAVERS SMITH, M.D.Dub., F.R.C.P.IREL., CONSULTING PHYSICIAN TO THE WEST MIDDLESEX HOSPITAL HON. ASSISTANT PHYSICIAN TO THE MILLER GENERAL HOSPITAL, S.E.

THE object of this address is to arouse interest in the neuroses and psychoneuroses (terms to be used synonymously) by indicating the important rôle they fill in the practice of a consultant physician, as indeed they do, in varying degrees, in every doctor's practice. In these days when doctors in general are educated to a high standard in the detection of organic disease, when they are fully alive to the assistance in so doing they can requisition from the pathologist, bacteriologist, biochemist, radiologist, regional specialist, and alienist, what is a common case to be sent to the residuary-legatee, the general consultant physician? It is the case of the ailing patient whom the local doctor has examined many a time and oft, perhaps employing one or more of the above specialities to help him, but failing to detect organic disease of any description, or sufficient to account for pressing subjective symptoms, becomes mystified, and, very often, "fed-up." This state of floundering mystification concerning a growing proportion of patients will remain prevalent in our profession till a knowledge of psychopathology is considered an essential item of liberal medical education. If practitioners were only aware of the almost unbounded possibilities of the neuroses to produce symptoms acute or chronic, or were as skilled in eliciting positive evidence of neuroticism as they are in finding organic disease, they would provide themselves with the correct diagnosis of many a mystery-to the detriment of residuary-legatees, such as myself. Hysterical, anxiety, and obsessional states, and others, are as definite as any organic condition and have as definite symptoms, the mental aspects of which, unfortunately, patients suppress, and proportionately overstress the bodily-the mental symptoms need skilled eduction by the doctor, the bodily are obtruded. Man, consciously and unconsciously, prefers a somatic interpretation of his suffering rather than the admission to his doctor, or even to himself, that he is not master of his mental fate and captain of his psychological soul. Thus it is that when emotion expresses itself in bodily manifestations, as it always does when strong, the patient's mental constitution predisposes him to accept such manifestations as those of bodily disease, and so those of a rational explanation of his feelings. Any system or organ of the body would provide examples of this psychological truism ; to-night I propose to exemplify it by Functional Nervous Disorders of the Heart.

* An Address delivered to the Lewisham Division, B.M.A., on Dec. 21 st, 1926 .
These terms are notoriously difficult to define : for the practical purposes of this address I shall mean by "functional," pertaining to ordained purpose ; by "nervous" (or neurotic), abnormal mentalisation, conscious or unconscious, but not including insanity ; by "disorders," the performance of a function excessively, insufficiently, irregularly, or hypersensitively, in the absence of disease usually accepted as such.

Emotion in Terms of Heart.

The heart is peculiarily liable to become the seat of nervous disorders, for the three following reasons :-

1. In the presence of emotional stress the heart is the organ that usually introduces itself most obviously and insistently to consciousness, for which reason it was long considered the originator and seat of the emotions, and even of temperament and character. Examine our language and it will be found that emotions, from of old and to the present day, are communicated in terms of heart, rarely of other organ. Thus, without any exhaustive search, are found such expressions as heart "in mouth," "quaked," " sank," " in boots," "lost,", standing for fear; heart " broken," "torn," "rent," "sore," " heavy," " cried out," " eaten out," for grief and despair ; "aching for," for pity ; "warm," "full," " large," " light," "lifted," " leaping," for love and delight ; " stout," "strong," "take heart," for bravery (certain primitives eat lions' hearts to acquire courage); " small," " hard," " cold," " black," " heartless," for cowardice and vice. The general expression "to take to heart" includes any persistent emotion. Is it a mere coincidence that the above terms expressive of predominating subjective sensations engendered by emotions should correspond with certain morbid anatomy findings in hearts grossly diseased, such as abnormalities in size, position, consistence, weight, and structural continuity? For diagnostic purposes it is safer to assume that this is not a coincidence, long or short armed; that rather is it a striking indication that emotional feelings can mimic those of gross disease, and that, as language tells, they did so mimic before our pathological knowledge was born.

2 . The popular conviction that the heart is the one and only vital organ, and can alone cause sudden death; that if it is sound there is no imminent danger; that if anything whatsoever is wrong with it, the end is near. Observe the gratification of patients when, in the course of an overhaul, one can say " you have got a good heart, anyhow."

3. Fear is instinctive in the presence of sudden danger, and so in the contemplation of sudden death. Many people can rationalise on the advantages of sudden death ; all instinctively fear it.

\section{The Mentality of the Doctor.}

In dealing with any cardiac patient it is useful to bear the above three points in mind, especially so with neurotic ones, also to realise that the neurotic is often the cheerful fatalist on the surface. Such an one consulting me recently concerning his 
heart, announced at .once, "Doctor, if you tell me that I have to drop dead to-day, I don't care a damn." Yet, when I was able to reassure him as to his heart, the measure of his delight contradicted his fatalism, and he proceeded to tell me of "the glorious funk" he had been in. It has here struck me that it might not be unprofitable to ramble as to the mentality of the doctor when dealing with cardiac conditions. At times he is not the superman he supposes himself--that is to say, he is not always mentally free, though often unconsciously, from the trammels of popular superstition in relation to sudden death. To his mind there could hardly be a mistake more calamitous to himself than that of "vetting" a heart, pronouncing it sound or insignificantly affected, and the patient concerned to die suddenly in a short time. There is within him the feeling that as the public would attribute this (erroneously) to abysmal prophetic ignorance, his reputation would be lost for ever; and thereby come into play from his unconscious mind fears based upon the forces of his self-preservative and, may be, family, instincts. Therefore he is unconsciously impelled, on hearing symptoms urgently stated by the patient or on minor cardiological findings, towards a bad prognosis-an embracing compromise between good and bad results. Hence springs much cardiological casuistry, such as "your heart is not quite right; you must take great care of yourself; never run for a bus or train; never worry or get excited"; advice that is received as tantamount to a sentence of sudden death if a neurotic patient is concerned, whereas very often no compromise need develop, unalloyed and desired optimism being warrantable. There is ever a world of interaction between the mind of a patient and that of his doctor-and their manners.

Again, we all come upon heart disease which will lead certainly to a fatal termination. It is then our duty to tell our opinion directly in the case of the responsible adult, and to the relatives concerned in the case of a child. But we ought to be mindful to avoid producing a "nerve-storm" which of itself may hasten the end ; and so, when justifiable, we should relieve the mind of the spectre of sudden death, lest such a fear beget a reality! I have known a nervous man to retire to his bed and determine to remain there, feeling worse than ever he had been, on the very day he had been able to take a considerable journey to consult a heart specialist who told him, truthfully but laconically, that he had grave heart disease. The patient took this as implying sudden death and soon, and concluded that bed would be the appropriate place for it, though the specialist had not ordered bed. The local doctor soon began to recognise that subjective symptoms were ensuing incompatible with the absence of increasing physical signs. I saw the patient, with his doctor, when he had been six weeks in bed, educed the sudden death idea, and gave the considered opinion that gradual heart failure was the more likely. The upshot was that the patient arose, found his cardiac limitations less urgent than he had felt them in bed, was comparatively happy, able to return to business for nearly three months. His doctor then observing further physical signs, wisely kept him at home, where he eventually died of gradual heart failure. Probably this psychological handling added to the length, certainly to the utility, of this patient's life. In certain forms of organic heart disease accurate prognosis is beset with difficulty, sometimes with impossibility. Most of us can look back through the years and recall patients who lived a long time, and some still alive, contrary to reasonable expectation; also converse instances. Never be overriden by fear of being an inaccurate prophet; it is deterrent to accurate observation, the basis of prophesy. In this connexion let me tell you of the case of an elderly doctor who had evidence of aortic and mitral valve lesions, and a myocardium not above serious suspicion. He was most importunate at every visit in demanding a cut-and-dry prognosis which I would not give him, for I could not. To gain his point he consulted Mackenzie, obtained the following prognosis at the bayonet-point, and recounted it to me: "If there were two precisely similar cases, as far as could possibly be ascertained, before me, it would not surprise me to learn ultimately that one had died suddenly within 24 hours, and that the other had lived usefully for years." Since then I have admired, and on occasions taken comfort from, the magnanimous recognition of his own prophetic limitations, as embodied in that prognosis of Mackenzie-there was the big man! It is beside the point that the patient did neither, but died in nine months of moderately gradual heart failure. Enough to have indicated that, as doctors; our own mentality is worthy of some study in dealing with heart patients, more so than with others.

Functional Nervous Disorders of the Heart.

Now to discuss, seriatim, certain functional nervous disorders of the heart, bearing in mind that each one of them may alike result from organic disease, to be carefully sought as a preliminary in every case.

\section{Fainting.}

The. cerebral ischæmia, the ultimate cause of the partial or complete loss of consciousness, is produced through the media of vagus inhibition of the heart, or through sympathetic determination of blood to the splanchnic area, or, may be, through auricular flutter. No doubt the endocrine glands also play a part. But the more minutely cases are studied (organic disease having been excluded) the greater the proportion of them reveals nervousness at various mental levels as the primary factor in producing the above subsequent trains of functional disorder. Can anyone reasonably doubt that fainting at the sight of blood, or on seeing an accident, or on hearing another in pain, or on feeling a trivial pain such as the prick of an 
inoculation needle, is of mental origin? True, the patient is usually unaware of this, and so will the doctor be who stops short of psychological investigation. To give some instances briefly.

(a) A hospital nurse used to faint on no occasion except when seeing a male patient vomit. Another elicited peculiarity was that she would cross a street rather than pass nearer the door of a public-house. A suppressed memory was restored of a drunkard father long dead, whom, one day, she still a small child, had seen reel from a public-house and vomit on the pathway. He then caught her and beat her for what she had observed.

(b) A lady, aged 50, took to fainting, but never did so except in the presence of her eldest sister who had returned from long residence abroad. Then, though they agreed passing well, at the slightest hint of disharmony between them the younger would faint. Childhood recollections produced many instances of sister rivalry and bullying on the part of the elder.

(c) A man, devoted to the turf, fainted several times at race meetings, and once at a cinema. Inquiry revealed that at each he had been witnessing a closely finishing race. But he had never associated this with previous war service in the R.F.A., when he once rode his gun " hell for leather" out of action to save its imminent capture, getting wounded in doing so.

(d) A man fainted on seeing his wife crush a fly. The association came up of having seen a man cut in two by a train years before.

(e) A man serving in France used to get faint at the sight of an aeroplane in flight, enemy or our own. The same stimulus caused faintness on his return, and once he fainted on seeing a small cloud in an otherwise clear sky. Eventually he recalled a dream, from which he had awakened in terror, of an aeroplane flying at him with two weird projections from underneath it. Asked to draw it, he drew a plane with two obvious claws. Gazing at his drawing he suddenly was seized with fear as back to the surface gushed a threat that an old nurse used to administer when he was unkind to his younger brother, "I'll get an eagle to fly away with you.'

(f) A man would get faint when a cold wind blew on his face. Years before he had had an occupation in N.W. Canada, entailing long tramps over the snow by himself. At those times he was obsessed by the thought "if I were to faint and fall now, nothing could save me "-but he never did then.

(g) A lady was given to fainting in church and in thunderstorms. Closer investigation revealed that in church it was the words "descended into hell" that affected her. Thunderstorms were associated with a long forgotten picture of hell in which lightning and other horrors loomed largely. As a tiny child hell was her dread; her wish was to go to Heaven with her father for ever.

The name of these cases is Legion ; yet, perhaps, these instances will suffice to make my point as to the value of some psychological investigation, though they are far from models of what complete psycho-analyses should be. These patients were all psychoneurotics who turned up in the guise of "weak heart," who benefited by discontinuation of attention to that organ, through the realisation of the mental origin of their faints.

\section{D.A.H. and Tachycardia.}

Mackenzie in the 1925 edition of "Diseases of the Heart " deplores the lack of precise knowledge of the cause of this common condition, and is evidently dissatisfied with its manifold current explanations, with which there is no time to deal here. In the 1913 edition of the same monumental work he observes how frequently " the cardiopath tends to become a neuropath." Had he lent his great ability to following up this line of investigation o I feel sure he should have concluded how much of more frequently neuropaths become functional ฏ cardiopaths. Reading statistics of large groups of 3 cases of D.A.H. in which a mere 5 to 10 per cent. $\stackrel{\Phi}{\complement}$ are attributed to neuroticism, I can but surmise.. that it had been counted only in blatant form, $\vec{F}$ and never systematically sought. When psychologically investigated D.A.H. is traceable to suppressed fear, or unconscious anxiety, or both. $\frac{\bar{c}}{\bar{N}}$ As concomitants of these emotions are usually one $\frac{\sigma}{\sigma}$ or more other manifestations-e.g., muscular $\mathbb{\mathbb { Q }}$ hypertension and tremor, quickened and deepened respiration, vasomotor commotion, diuresis, $\overrightarrow{0}$ diarrhœa, vomiting (sick with fright, often called "gastritis"), ready confusion of mind, and $\vec{\omega}$ diminished concentration. On inquiry into the $\frac{\rho}{8}$ immediate causes of aggravations of D.A.H., whate to the subjects of it are emotional situations, are 3 . almost constantly found. As examples may N be cited sudden noise, seeing or hearing a row. (a man had to retire from the monkey-house $\vec{\omega}$ with a "heart attack" on seeing two of its? inmates start to scrap), any semblance of danger, ? anything suddenly happening to another person, $\vec{c}$ and so forth. Far too much stress has beenc laid upon exertion as a precipitant of " heart $ه$ attacks" in D.A.H. Is the emotional elemento likely to be absent in the man who is taking aN walk, or at his work, when his idea is that he isं straining his heart? Or from the man who wheno ordered to exert himself by his doctor with the views to testing "exercise tolerance," when, to his mind, looms sudden death as the consequence? It is very difficult to separate emotional effects upon the heart from those due to exertiono흘 or even to exercise. Try to do it in this way. Let a patient sit quietly telling his symptoms till the physical effects if normal of his entry have time. to pass off. Then unobtrusively count his pulseo whilst talking of an unemotional subject. Thent. say, "please do not stir, I am going to examine your heart," and open his clothes yourself. Put. your stethoscope (portentous instrument to the cardiac neurotic) to your ears and his heart deliberately. By this time the heart- and pulse-rates may have increased surprisingly (up to 60 , I have observed) in the absence of any element of exertion How is this to be explained otherwise than that ons is dealing with nervousness, having its focus upoin the heart, in the absence of auricular flutter and paroxysmal tachycardia. And, to my thinking $\omega_{t}$ as it is so evident that a fleeting emotion mak precipitate an individual attack of D.A.H., is reasonable to conclude that stronger or deepe emotion may originate the disorder, which proves to be the rule in direct proportion to the depth of psychological investigation.

Before leaving the subject it may be useful tक्ष mention the associations that may be found is D.A.H. and organic heart disease.

(a) The D.A.H. may be a pure complication; it if often to be səen supərvening in the nervous or potentialy 
so, especially when a superabundance of stethoscopic attention is given to the organic lesion. During the war I have seen outbreaks of D.A.H. spread amongst neurotic members of hospital wards, from the presence of a few organic cases.

(b) D.A.H. may aggravate heart lesions, valvular or myocardial, more notably if these are inflammatory, by causing increased force and frequency.

(c) D.A.H. may be misinterpreted organic disease, especially as, when prolonged, it may produce some cardiac enlargement chiefly right-sided, be accompanied by functional murmurs, and provoke common subjective symptoms.

(d) Organic disease may be diagnosed D.A.H., and this more often in subjects manifestly neurotic otherwise.

(e) I am not impressed with the view that latent organic heart disease affords a frequent origin of D.A.H. In my experience it is more of ten the case that D.A.H. is a factor in determining previous or supervening infections to the heart.

\section{Heart Pain.}

If every patient who complains of pain in, around, through, or under the heart (and who has such pain, mark you !) were actually to drop dead suddenly (the usual concept of the consequence of pain in that region), our nervous population would be going down like nine-pins. On the other hand, as we all know (likewise the laity) a very slight attack of cardiac pain may be the prelude to a severe one of angina pectoris and sudden death-immediately, or delayed for years, or may herald gradual heart failure. No wonder, then, that heart pain is so commonly a reason for consultations, neurotics providing a large proportion of them! Qua pain alone, there are some helpful points in differentiating the organic from the neurotic.

Organic-(a) More frequent in the elderly and in males (excluding infectious carditis and pericarditis); (b) pain that is not described as originating in the heart, but indicated as substernal, in left arm and forearm, root of neck, sometimes as epigastric ; $(c)$ pain induced by exertion alone, best recognised by the history of beginning to appear during a wonted exertion, hitherto painless.

Neurotic-(a) More frequent in the youthful and in females; (b) pain is more dependent on mental states apart from exertion which, as before said, often provides an emotional stimulus (a patient of mine was all the more convinced that his heart was diseased because the evening before I saw him he had got his worst attack of heart pain when he had been lolling quietly for an hour in an armchair. Inquiry revealed he was reading the newspaper, had just turned over a page, and his eyes had caught "Coroner's Inquest ") ; (c) the pain is often influenced by a concept-e.g., it may be referred to the left axillary region, from the idea "the heart is on the left side." Or stress being laid upon the quality of the pain may betray concepts-e.g., "bursting," "stabbing," " gnawing", (fatal processes as far as a heart is concerned). In my experience hyperæsthesia is little help ; it may be acute in a cardiac neurosis, as it may be in an abdominal one. Of course, the paramount point in the differential diagnosis is the exhaustive search for any organic condition that can produce cardiac pain, but if no such disease is found the examination should be pursued for positive mental evidence of neurosis, failing which a diagnosis remains unmade. Here, again, a compromise is too frequently arrived at. The patient is told that no serious disease has been discovered, and that the cardiac pain is due to a windy stomach from indigestion. True, the indigestion, the wind, and the cardiac pain can be an interacting trinity, but it is one prone to emanate mentally.

(The concluding portion of this section, dealing with Arrhythmia, Giddiness, Night Starts, Palpitation, and Breathlessness will appear in the next issue.)

\section{THE CARE AND FEEDING OF THE PREMATURE INFANT.*}

\author{
BY
}

\section{DONALD PATERSON, M.B. EdIN.,} M.R.C.P. LoND.,

PHYSICIAN FOR DISEASES OF CHILDREN AT THE WESTMINSTER HOSPITAL AND PHYSICIAN TO OUT-PATIENTS, THE HOSPITAL FOR SICK CHILDREN, GREAT ORMOND-STREET.

To have a clear idea of the difficulties of the care and feeding of the premature infant it is necessary to consider, first, why the child has been born prematurely, and the possible effects on the child of these pathological factors, and secondly, what damage may have occurred to the infant during or after birth. Some of the factors which, acting through the mother, may produce premature labour are syphilis, nephritis, (toxæmia of pregnancy), heart disease, acute infectious fevers, chronic infections of the uterus, multiple pregnancy (twins or triplets), poisoning of the mother by lead, arsenic, or other metals. Malformations or abnormalities in the fœtus itself, such as cases of hydrocephalus or absence of the abdominal wall, may cause premature birth. Miscarriage occurs sometimes without any known cause. To realise what damage may occur to the infant at birth one must consider the possibilities of hæmorrhage, especially cerebral hæmorrhage, occurring during labour. In the premature infant the vessels are so poorly formed and supported that, although labour may be extremely easy, trauma and pressure is withstood badly and the slight moulding of the head during birth tends to pull on and tear the fine vessels of the brain and meninges, causing hæmorrhage. Another factor is the tendency for premature infants to bleed. The coagulation time is lengthened in many premature infants, and also their "bleeding time." Whether this be due to the fact that these infants suffer from a deficiency of calcium, since that salt is largely given by the mother in the last two months of intra-uterine life, it is difficult to say. Certainly

* A Lecture delivered at the Hospital for Sick Children on Feb. 10th, 1927 . 